\title{
A Recycling Technique of Iron Phosphate Containing Sludge
}

\author{
Takahashi Masaaki $^{{ }^{*}}$, Takemoto Yukimasa and Hukaya Yuriko ${ }^{2}$ \\ 1. Yokkaichi University, Faculty of Environmental and Information Science, Mie, 512-8512 Japan \\ 2. Sharp Corporation, AVC Liquid Crystal Display Group, Kamevama, Mie, 519-0169 Japan
}

\begin{abstract}
In the processes of wastewater treatment, significant amounts of iron phosphate containing sludge is discharged. One of the recycling methods of this sludge, alkalization treatment is investigated. aq. solution of sodium hydroxide is added to the dehydrated sludge. Iron phosphate in the sludge react with sodium hydroxide, forming sodium phosphate and iron hydroxide containing-sludge at room temperature. The recovered phosphorus contained $91 \%$ of phosphorus as the form of $\mathrm{Na}_{3} \mathrm{PO}_{4}$, and iron hydroxide-containing residue has $93 \%$ of iron as $\mathrm{Fe}_{2} \mathrm{O}_{3}$.
\end{abstract}

Key word: Iron phosphate, sludge, sodium phosphate, recycle.

\section{Introduction}

Phosphorus is widely used as a reagent inmetal engineering or the electric industry, especially liquid crystal manufacture. In order to remove phosphorus from waste water, many removal methods are introduced [1, 2]. As a conventional method, phosphorus removal using iron compound was widely introduced [3, 4], resulting in a large amount of phosphorus containing sludge to be discharged. Almost all of the phosphorus in the sludge is thought to exist as a form of iron phosphate. Iron phosphate can be used for surface treatment agent or exterminator and recently, a raw material of lithium battery.

However, purity of the recovered iron phosphate is low for these usages, purification is regarded as cost ineffective. Iron phosphate is not soluble in water, therefore, is not available for fertilizer, and much of the sludge is discharged to landfill site.

\section{Methods}

Iron phosphate is expected to react with strong alkali like sodium hydroxide or potassium hydroxide shown

Corresponding author: Takahashi Masaaki, Researcher, research field: environmental technology. E-mail: machaaki@amigo.ne.jp. in Eq. (1). In order to recover the phosphorus from sludge, a recovery method (Fig. 1) using alkali has been investigated [5]. The properties of the phosphorus containing sludge are not the same, and the chemical composition depends on the source or water treatment methods. One of the recycling methods of this sludge, alkalization treatment was investigated about dehydrated sludge (Table 1), which was collected from the wastewater of an electric factory [6].

$$
\mathrm{FePO}_{4}+\mathrm{MOH} \rightarrow \mathrm{Fe}(\mathrm{OH})_{3}+\mathrm{MPO}_{4}
$$

M: Alkali metal.

$\mathrm{MPO}_{4}$ : Alkali metal phosphate.

\section{Results and Discussion}

\subsection{Reactivity of the Sludge to Alkali}

Iron phosphate in the sludge is expected to decompose by the addition of a strong alkali, and form ferric hydroxide and another phosphate salt. In order to confirm a reactivity of alkalis against the iron phosphate in the sludge, aq. solution of sodium hydroxide, sodium carbonate or calcium hydroxide was respectively mixed to the sludge. After $1 \mathrm{~h}$ of stirring, $\mathrm{pH}$ value of the mixture was measured in grass electrode method. Elution of the phosphorus from 
Table 1 Composition of the sludge (unit: \%).

\begin{tabular}{|c|c|c|c|c|}
\hline Component & $\mathrm{Fe}_{2} \mathrm{O}_{4}$ & $\mathrm{P}_{2} \mathrm{O}_{5}$ & $\mathrm{Al}_{2} \mathrm{O}_{3}$ & Others \\
\hline Content (\%) & $58.1^{*}$ & $34.2 *$ & $6.0^{*}$ & $1.7^{*}$ \\
\hline \multicolumn{5}{|c|}{ Water content; $70 \%$. } \\
\hline \multicolumn{5}{|c|}{ *Dry sample base. } \\
\hline \multicolumn{5}{|c|}{ Alkali(MOH) + Water } \\
\hline Sludge & & & \multicolumn{2}{|c|}{ Evaporation } \\
\hline \multicolumn{5}{|c|}{$\begin{array}{l}\text { Iron hydroxide containing sludge } \\
\qquad\left(\mathrm{Fe}(\mathrm{OH})_{3}\right)\end{array}$} \\
\hline
\end{tabular}

Fig. 1 Phosphorus recovery method.

sludge was determined by chemical analysis. The color of the iron phosphate is light charcoal, contrarily, the color of ferric hydroxide is dark charcoal, The color change from light charcoal to dark charcoal indicate a reaction of iron phosphate and alkali. The phosphorus elution and color change was found by addition of sodium hydroxide. However, no apparent reaction was found by addition of sodium carbonate and calcium hydroxide (Table 2). This result was showed that strong alkali conditions $(\mathrm{pH}>13)$ were needed, and substance like sodium hydroxide could react with iron phosphate, and form sodium and phosphate.

\subsection{Analysis of the Recovered Material}

In order to confirm the formation of sodium phosphate, $200 \mathrm{ml}$ of aqueous solution of sodium hydroxide $(\mathrm{NaOH} 20 \mathrm{~g})$ was added to $40 \mathrm{~g}$ of this sludge. Like 3.1, the color of the sludge changed to dark charcoal, and precipitated. This sediment considered ferric hydroxide, was formed by the reaction of iron phosphate and sodium hydroxide. The sediment was collected as ferric hydroxide containing residue by filtration using filter paper (No. 2, ADVANTEC, Tokyo, Japan) followed by drying at $105{ }^{\circ} \mathrm{C}$ (Table 3). Phosphorus which eluted in the filtrate was also recovered by evaporation in an oven at $180{ }^{\circ} \mathrm{C}$. The composition of recovered materials were analyzed by florescence X-ray spectroscopy (Table 4). The recovered ferric hydroxide containing residue has $93 \%$ of iron component (as $\mathrm{Fe}_{2} \mathrm{O}_{3}$ ), and is regarded to be the same as conventional iron recycling. Recovered phosphorus (amount $8 \mathrm{~g}$ ) contains $91 \%$ of phosphorus (as the form of $\mathrm{Na}_{3} \mathrm{PO}_{4}$ ), and is considered to be made of $\mathrm{Na}_{3} \mathrm{PO}_{4}$ by chemical composition and recovery condition $(\mathrm{pH}>13)$. The phosphorus recovery rate is estimated to be $92 \%$ from the phosphorus content of the sludge.

\subsection{Further Investigation}

As mentioned in 3.2 sodium phosphate was recovered from sludge, however, recovery of the sodium phosphate needs liquid-solid separation or evaporation processes. Some techniques which convert sodium phosphate HAP (calcium phosphate hydroxyl apatite) or MAP (Magnesium ammonium phosphate) $[7,8]$ are investigated [5]. With fertilizer, phosphorus solubility from sludge seems to have priority, and high

Table 2 Reactivity of alkali to the sludge.

\begin{tabular}{llll}
\hline Compound & $\mathrm{NaOH}$ & $\mathrm{Na}_{2} \mathrm{CO}_{3}$ & $\mathrm{Ca}(\mathrm{OH})_{2}$ \\
\hline $\mathrm{pH}$ & 13 & 11.3 & 11.6 \\
P-elution* & Found & Not found & Not found \\
Color change & Found & Not found & Not found \\
\hline
\end{tabular}

*P-elution: Phosphorus elution.

Table 3 Amount of the recovered materials.

\begin{tabular}{llll}
\hline & Amount $(\mathrm{g})$ & State & Color \\
\hline $\mathrm{Fe}$ & 9 & Sludge & Deep charcoal \\
$\mathrm{P}$ & 8 & crystal & White \\
$\mathrm{R}$ & 40 & Sludge & Light charcoal \\
\hline
\end{tabular}

Fe: Ferric hydroxide containing sludge (dry).

$\mathrm{P}$ : Recovered sodium phosphate (dry).

R: Raw sludge (water content $70 \%$ ).

Table 4 Compositions of the recovered materials.

\begin{tabular}{llllll}
\hline & $\mathrm{P}_{2} \mathrm{O}_{5}$ & $\mathrm{Fe}_{2} \mathrm{O}_{3}$ & $\mathrm{Al}_{2} \mathrm{O}_{3}$ & $\mathrm{Na}_{2} \mathrm{O}$ & $\mathrm{O}$ \\
\hline $\mathrm{R}$ & 34.2 & 58.1 & 6.0 & $<1.0$ & $<1.0$ \\
$\mathrm{~F}$ & 2.8 & 93.3 & $<1.0$ & $<1.0$ & 3.0 \\
$\mathrm{P}$ & 61 & $<1.0$ & 3.1 & 30 & 5.0 \\
\hline \multicolumn{2}{l}{ Unit: $\%$}
\end{tabular}

R.: Raw sludge.

Fe: Iron hydroxide containing sludge.

P.: Recovered sodium phosphate. 
O: Others.

solubility of the phosphorus from the sludge is considered to be obtained by only the addition of alkali metal hydroxide. In order to find a simple way to make fertilizer, an investigation of phosphorus solubility from the mixture of the sludge and $\mathrm{NaOH}$ was carried out.

$20 \mathrm{~g}$ of the sludge was mixed with $20 \mathrm{ml}$ of aq. $\mathrm{NaOH}$ solution (containing $5 \mathrm{~g}$ of $\mathrm{NaOH}$ ), and dried at $105{ }^{\circ} \mathrm{C}$ (Mixture A). The color of mixture A became dark charcoal because of the reaction of iron phosphate and sodium hydroxide. In order to confirm phosphorus solubility from mixture A, the mixture was added $1,000 \mathrm{ml}$ of water for elution test, and stirred $1 \mathrm{~h}$, and settled $1 \mathrm{~h}$. Later, sediment formed by reaction was separated by filtration using filter paper, and dried at $105{ }^{\circ} \mathrm{C}$ for analysis. The phosphorus concentration of sediment (from mixture A) has decreased by phosphorus elution (Table 5). This result shows the phosphorus in the mixture A is soluble in water, and available for phosphorus feeder.

However, strong alkali conditions are not good for fertilizer, and neutralization is regarded as necessary. In order to make a neutral phosphorus soluble mixture, $\mathrm{H}_{2} \mathrm{SO}_{4}$ was added to the mixture of $\mathrm{NaOH}$ and sludge, and neutralized sludge $(\mathrm{pH}=7)$ was dried at $105{ }^{\circ} \mathrm{C}$ (mixture B). Mixture B was mixed with $1000 \mathrm{ml}$ of water for elution teat, and sediment was collected for analysis like same way of the mixture A. The phosphorus concentration of sediment from mixture B is half of raw sludge, which means phosphorus solubility decreased by neutralization. To make neutral fertilizer, phosphorus solubility of mixture B should become high, and further investigation is needed.

Table 5 Composition of sample A and B (Unit: \%).

\begin{tabular}{lcllllc}
\hline & $\mathrm{P}_{2} \mathrm{O}_{5}$ & $\mathrm{Fe}_{2} \mathrm{O}_{3}$ & $\mathrm{Al}_{2} \mathrm{O}_{3}$ & $\mathrm{Na}_{2} \mathrm{O}$ & $\mathrm{CaO}$ & $\mathrm{O}^{*}$ \\
\hline $\mathrm{A}$ & 2.6 & 90.9 & 1.2 & $<1.0$ & 3.1 & 2.0 \\
$\mathrm{~B}$ & 15.5 & 71.6 & 6.0 & 1.5 & 1.9 & 3.5 \\
$\mathrm{C}$ & 34.2 & 58.1 & 6.0 & $<1.0$ & $<1.0$ & $<1.0$ \\
\hline
\end{tabular}

A: Sample A.

B: Sample B.
C: Raw sludge (dry). $\mathrm{O}^{*}$ : others.

\section{Conclusions}

One of the recovery methods of phosphorus from iron phosphate containing sludge, alkalization processes was investigated. An aq. solution of sodium hydroxide was added to the sludge. Iron phosphate in the sludge reacted with sodium hydroxide, formed sodium phosphate and ferric hydroxide at room temperature. The ferric hydroxide was precipitated, and collected as a residue by filtration followed by evaporation. Sodium phosphate which eluted in the filtrate was also recovered by evaporation. Almost of the iron phosphate in the sludge reacted with sodium hydroxide and was converted into sodium phosphate. The recovered ferric hydroxide-containing residue is mostly made of iron $\left(93 \%\right.$ as $\left.\mathrm{Fe}_{2} \mathrm{O}_{3}\right)$, and phosphorus is considered to be made of $\mathrm{Na}_{3} \mathrm{PO}_{4}$. A simple way to make fertilizer, the phosphorus solubility of sludge and $\mathrm{NaOH}$ mixture was investigated. The phosphorus solubility of the mixture of $\mathrm{NaOH}$ and sludge became low by neutralization, and more investigations are needed.

\section{Acknowledgements}

The author wish as to express much appreciation to Mr. Motoki Yoshimura (Mie Pref. Institute of Health and Environmental Research) for his assistance on the chemical analysis of the sludge.

\section{References}

[1] Groterud, T. and Smoczynski, L. 2002. "Phosphorus Removal from Water by Means of Electrolysis." Water Research 20: 667-9.

[2] Jyokasou Association (JSA), http://www.jsa02.or.jp/05koho/index.html.

[3] Nittetsu Mining CO. "LTD: Multifunctional Inorganic High-Polymer Flocculant." Polytetsu, https://www.nittetsukou.co.jp/rdd/tech/tech_polyiron.html.

[4] Tokyo Metropolitan Government Bureau of Sewage, "Phosphorus Removal from Filtrate Water of Sewage Sludge."

http://www.gesui.metro.tokyo.jp/gijyutou/gm12/nenpou2 001/04-03.pdf. 
[5] Sano, A., Kanomata, M., Inoue, H., Sugiura, N., Xu, Kai-Qin and Inamori Y. 2012. "Extraction of Raw Sewage Sludge Containing Iron Phosphate for Phosphorus Recovery." Chemosphere 89: 1243-47.

[6] Takahashi, M., Takemoto, Y. and Hukaya, Y. 2009. "Recycle Technique of Iron Phosphate Containing Sludge", In Proceedings of R'09 Twin World Congress in Nagoya, 267.

[7] Daiki Ataka Engineering Co. Ltd. "Phosphorus Recovery
System."

[8] Sano, A., Xu, Kai-Qin., Kanomata, M,. Sugiura, N., Inoue, H. and Kondo, T. et al. 2012. "Phosphorus Recovery from Sewage Sludge for An On-Site Domestic Wastewater Treatment Facility (Johkasou) with Phosphorus Removal by Iron Electrolysis and Application of Recovery Material as Fertilizer." Johkasou Research 24: $1-7$. 